\title{
In Vitro Whitening Properties and Antioxidative Potentials of The Extracts of Three Melastoma Leaves Species (M. malabathricum, M. hirta and M. decemfidum)
}

\author{
Nur Fauwizah Azahar 1, Siti Salwa Abd Gani *1,2, Uswatun Hasanah Zaidan 1,3, Paiman Bawon ${ }^{4}$, Mohd Izuan Effendi \\ Halmi 5 \\ ${ }^{1}$ Halal products Research Institute, Universiti Putra Malaysia, 43400 UPM Serdang, Malaysia \\ 2Department of Agriculture Technology, Faculty of Agriculture, Universiti Putra Malaysia, 43400 UPM Serdang \\ ${ }^{3}$ Department of Biochemistry, Faculty of Biotechnology and Biomolecular Sciences, Universiti Putra Malaysia, 43400 UPM Serdang \\ ${ }^{4}$ Department of Forest Production, Faculty of Forestry, Universiti Putra Malaysia, 43400 UPM Serdang, Malaysia \\ ${ }^{5}$ Department of Land Management, Faculty of Agriculture, Universiti Putra Malaysia, 43400 UPM Serdang, Malaysia
}

Correspondence Author: Siti Salwa Abd Gani, Department of Agriculture Technology, Faculty of Agriculture, Universiti Putra Malaysia

Received date: 12 May 2019, Accepted date: 24 June 2019, Online date: 28 June 2019

Copyright: (C) 2019 Nur Fauwizah Azahar, et al. This is an open-access article distributed under the terms of the Creative Commons Attribution License, which permits unrestricted use, distribution, and reproduction in any medium, provided the original author and source are cre dited.

\begin{abstract}
The skin whitening and antioxidant properties from plant extract is the key to replace synthetic cosmetic formulation and also to obtain safer source with better biological activities. The present study was designed to investigate the antioxidant and tyrosinase inhibitory activities of the three Melastoma leaves extracts $(M$. malabathricum, M. Hirta and M. Decemfidum). The antioxidant activity was examined by two different methods namely total anthocyanins content (TAC) and total flavonoid content (TFC). The new findings have shown that all the tested exhibited higher flavonoid content in the range 2.27-5.65 mg/ QE/g of extract and $0.37-3.24 \mathrm{mg} / \mathrm{g}$ of anthocyanin content. Tyrosinase inhibitory activity was performed with L-DOPA as substrate and from the results, all Melastoma leaves plant exhibited good whitening effects in the range $30.7 \%-70.1 \%$ where $M$. malabathricum was recorded to show highest level of inhibitory activity. Based on the statistical analysis, there were positive correlation $(P<0.05)$ between antioxidant activity of TFC, TAC and tyrosinase activity. Hence, it can be concluded that all Melastoma plant could be a good source for finding natural active whitening properties and antioxidants potentials for the utilization in cosmeceuticals, medicinal and nutraceuticals applications.
\end{abstract}

Keywords: Melastoma; Antioxidants; Flavonoid content; Anthocyanin content; Tyrosinase inhibition

\section{INTRODUCTION}

In our body, the skin accounting of $15 \%$ of total weight. Therefore, it plays an important role to protect our body from external stressor such as ultraviolet radiation (UV). Every day, the UV radiation from the sunlight is the most common factor that can contribute harmful adverse effects, especially to the human skin. It results in the alternations in the composition of the skin such as collagen reduction and degeneration, accumulation of elastic fibres and also deposition of glycosaminoglycan [1]. Therefore, over time, the skin will appear the sign of ageing such fine wrinkles, hyperpigmentation, etc. The over exposure of skin to the UV radiation also induced the secretion of melanin. Melanin is the key pigment for the colour of human skin in the epidermal layers. It produced by a pathway called melanogenesis which initiated by the rate limiting enzymes called tyrosinase (phenol oxidase). Tyrosinase enzymes catalyse three steps of melanin biosynthesis including the hydroxylation of tyrosine to 3,4-dihydroxyphenyllalanine (DOPA), oxidation of DOPA to DOPA quinone and oxidation of 5,6 dihydroxyindole to indolequinone. Melanin formation is considered to be deleterious to colour quality. Therefore, the enzyme tyrosinase is the important target for finding out the skin lightening agents either from natural or synthetic sources. In recent times, tyrosinase inhibitors are used as a treatment for whitening agents, for example, arbutin, hydroquinone and kojic acid are used to lighten the human skin. According to [2] they are large numbers of tyrosinase inhibitor commercially in the market; however, only a few of these are used today as the majority of them show side effects or low effectiveness. Hence, there has been much attention focussed on the application of natural plant extracts as one of the alternative sources as skin whitening agents in the cosmetic industry.

It is well known that plants are important sources of compounds with different activities such as antimicrobial, anti-diabetic, anti-oxidant and anti-cancer [36]. The medicinal plants are a rich source of bioactive chemicals and its ability to scavenge the free radicals. Therefore there are growing interests in finding natural tyrosinase inhibitors. It has been investigated that anisaldehyde, quercetin and recently dalenin are some of the significant tyrosinase inhibitors that have been isolated from plant sources [7].

Melastoma is the family of Melastomataceae. In the southeast region including Malaysia, a genus of Melastoma comprises of 22 species, two subspecies and three varieties which can be grouped by the colour of the flower petals such as dark-purple magenta, light-pink magenta and white [8]. Traditionally, the members of this plant use to treat diabetes, diarrhea, wound healing and lowering the high blood pressure [9]. Moreover, it has been investigated that these plants exhibit several secondary metabolites such as phenolic and flavonoid compounds which are significant for the treatment of various diseases such as anticancer and antioxidant [10]. Moreover, a study done by several researchers found that several plant parts such as the leaf of Melastoma contains several phytochemical 
Citation: Nur Fauwizah Azahar, et al., 2019. In Vitro Whitening Properties and Antioxidative Potentials of The Extracts of Three Melastoma Leaves Species (M. malabathricum, M. hirta and M. decemfidum). Journal of Applied Sciences Research., 15(3): 6-11. DOI: 10.22587/jasr.2019.15.3.2

constituents such as triterpenes, flavonoid, steroids, tannins and saponins which contribute to antioxidant activity [11]. On the basis of its traditional use and literature reference, this study was designated to evaluate the in-vitro three different Melastomaceae family species namely M. malabathricum, M. Hirta and M. Decemfidum for their whitening properties and antioxidant potentials towards total anthocyanin content (TAC) and total flavonoid content (TFC) which can fulfil the needs for alternatives medicines and cosmeceuticals use remedy.

\section{Objectives}

To determine the anti-tyrosinase activity and antioxidant potentials by estimating total flavonoid and total anthocyanin content in three different Melastoma species (M. malabathricum, M.hirta and M. decemfidum) leaves extract as a potential in cosmetic products.

\subsection{Chemicals}

\section{MATERIALS AND METHODS}

Aluminium chloride, 3,4-dihydroxy-L-phenylalanine (L-DOPA), lyophilised mushroom tyrosinase and kojic acid were purchased from Sigma Aldrich (Steinheim, Germany).

\subsection{Plant material}

The leaves of two species Melastoma (M. malabathricum and M. Hirta) were collected at their natural habitat at Ayer Hitam, Hutan Puchong, Selangor, Malaysia in August to October 2017. Meanwhile, M. Decemfidum was collected in the southern province of Malaysia. All leaves were further identified by Dr Paiman bin Bawon, a senior lecturer from Faculty of Forestry, Universiti Putra Malaysia. Next, the whole leaves samples were washed with tap water to remove dust and dried under a shady area at room temperature $\left(27 \pm 2^{\circ} \mathrm{C}\right)$ for one to two weeks. According to literature, this process did not cause any destruction of the bioactive compounds of the leaves as proven by the availability of antioxidant, anti-inflammatory, anti-bacterial and anti-nociceptive [12].

\subsection{Preparation of plant extracts}

The air-dried leaves were ground using a mechanical grinder machine into a powder form. Next, the Melastoma leaves were mixed with solvent extraction (hexane, ethyl acetate and methanol in the ratio of $1: 10(\mathrm{w} / \mathrm{v})$ for two times with stirring at room temperature. The mixtures were filtered using filter paper (Whatman No.1) and evaporated using rotary evaporator (Yamato, Rotary Evaporator, model-RE 801, Japan) until crude extracts were obtained. Before use, the crude extract will be dissolved in extraction solvent to a final concentration of $1000 \mu \mathrm{g} / \mathrm{mL}$.

\subsection{Determination of anthocyanins content}

Total anthocyanin contents (TAC) of all Melastoma leaves extract was determined based on a method described by [13]. Briefly, the leaves extract was diluted with $60 \%$ ethanol ( $\mathrm{pH} 3.0$ ). Next, the reading of TAC was calculated based on the absorbance value at $535 \mathrm{~nm}$. All tests were performed in triplicate. The TAC was calculated, as shown in (Eq. 1).

$\mathrm{TAC}=\frac{A_{535 \mathrm{~nm}} \times \mathrm{V} \times N}{98.2 \times m}$

where TAC is total anthocyanin content in extract ( $\mathrm{mg} / \mathrm{g}$ ), $A_{535 \mathrm{~nm}}$ is absorption value measured at $535 \mathrm{~nm}, V$ is total volume (mL), $N$ is dilution multiple, 98.2 is extinction coefficient at $535 \mathrm{~nm}$, and $m$ is mass of the sample.

\subsection{Determination of total flavonoid content}

A method from [14] was adopted to determine the total flavonoid content in all Melastoma leaves extracts. The reaction mixture was prepared by mixing $100 \mu \mathrm{L}$ of each plant extract $(100 \mu \mathrm{g} / \mathrm{mL})$ with $2 \% \mathrm{AlCl}_{3}$ solution and incubated for an hour at room temperature. The absorbance was evaluated using spectrophotometer at $\lambda=415 \mathrm{~nm}$. All samples were prepared in triplicate for each analysis, and the mean value of absorbance reading was obtained. A standard solution of quercetin was also prepared using the same procedure to obtain the calibration line. Based on the measured absorbance, the total flavonoids content was expressed in terms of quercetin equivalent ( $\mathrm{mg}$ of quercetin/g of extract).

\subsection{Determination of anti-tyrosinase activity}

Skin whitening effect was determined using the modified dopachrome method with L-DOPA as substrate [15]. The assay was conducted in a 96-well microliter plate and a plate reader was used to measure the absorbance at $450 \mathrm{~nm}$. Samples were diluted $(1000 \mu \mathrm{g} / \mathrm{mL})$ using solvent extraction. Each well contained $20 \mu \mathrm{L}$ of sample with $138 \mathrm{uL}$ phosphate buffer solution (PBS) and $2 \mu \mathrm{L}$ mushroom tyrosinase solution (2687 U/ $\mathrm{mg}$ solid, $9.31 \mathrm{mg}$ tyrosinase). The incubation was done at $37{ }^{\circ} \mathrm{C}$ for 90 minutes and followed $40 \mu \mathrm{L}$ of L-DOPA (2.5 mM in PBS). Each sample was accompanied by a blank that had all the components except L-DOPA. The percentage inhibition of the tyrosinase activity was calculated using the following equation (Eq. 2). Kojic acid and ascorbic acid was used as the positive control.

Percentage inhibition $=\underline{\text { Abs control }- \text { Abs sample }} \times 100 \%($ Eq.2)

Where abs - absorbance Abs control

\subsection{Statistical analysis}

The data of anti-oxidant activities were done in triplicates to test the reproducibility of them. All results are presented as mean \pm SPSS (statistical software version 7.0) was used for statistical analysis of results. Correlations among data obtained were calculated using Pearson's correlation coefficient (r) to assess the association between the different assays. The values of $\mathrm{p}<0.05$ were considered statistically significant.

\subsection{Antioxidant activity}

\section{RESULTS AND DISCUSSIONS}

Natural plant source that is traditionally used in folk medicine is particularly interesting for determination of their antioxidant effects. Several methods and modifications have been used and proposed for seeking their wide therapeutic values and bioactive compounds [16]. In this study, two methods of antioxidan assessment, total flavonoid content and total anthocyanin content were evaluated. Flavonoids are plant secondary metabolites and potent class of natural products $[17,18]$. Moreover, they cater major benefits which consist of a large group of polyphenolic compounds [19]. According to [20] there are 6500 varieties of flavonoids have been reported such as in Zingiber officinale Roscoe (ginger) [21], Nelumbo nucifera (lotus) [22], Nepeta septemcrenata (catnip) [23] and others. Meanwhile, anthocyanins are a subgroup of plant compounds known as flavonoids, and it is one of the largest and most potent group of water-soluble pigments in the plant kingdom [24,25]. Anthocyanins occur in all higher plants, including in leaves where the bioactive compounds can act as a protective agent against a variety of diseases such as cardiovascular diseases and various types of cancer. In this present works, the antioxidant activities were determined from three Melastomataceae family species, namely M. malabathricum, M. hirta and M. decemfidum. Hence, by analyzing data obtained by these two methods, they could deliver a more precise description of the anti-oxidant activity in the studied samples.

From the observations, the three Melastoma species leaves of M. malabathricum, M. hirta and M. decemfidum showed flavonoid content, and anthocyanin content in the range from $2.27-5.65 \mathrm{mg} / \mathrm{QE} / \mathrm{g}$ of extract and $0.37-3.24 \mathrm{mg} / \mathrm{g}$ respectively (Table 1). The Melastoma plant from M. malabathricum leaves extract ranged from 4.17-5.65 mg/QE/g extract showed the highest flavonoid content as compared to other Melastoma leaves extract. Our finding also correlates with the finding from [9] where the phytochemical screening of M. malabathricum plant showed high content of flavonoid 14.7 and $85.8 \mathrm{mg} / \mathrm{g}$ in both aqueous and ethanol 
Citation: Nur Fauwizah Azahar, et al., 2019. In Vitro Whitening Properties and Antioxidative Potentials of The Extracts of Three Melastoma Leaves Species (M. malabathricum, M. hirta and M. decemfidum). Journal of Applied Sciences Research., 15(3): 6-11. DOI: 10.22587/jasr.2019.15.3.2

extract. Meanwhile, a study done by [10] showed the leaf part of M. malabathricum exhibited $60.29 \pm 3.33 \mathrm{mg}$ of QE/g of flavonoid content which higher amount than other parts of plants such as flower, fruits and stem in the ranged from $1.63-38.17 \mathrm{mg}$ of QE/g. Hence, it shows that plant part such as leaves could contribute to the highest antioxidant activity and there is no doubt that generally leaves part are selected and reported for antioxidant studies by the most researcher [26]. Also, the present data also shows that the high content of the flavonoid could be associated with the high level of antioxidant activity in the extracts due to the fact the flavonoids are the main group of polyphenols which able to scavenge radical oxidizing species [9]. Meanwhile, the total flavonoid content of $M$. hirta leaves ranged from 2.27- $5.61 \mathrm{mg} / \mathrm{QE} / \mathrm{g}$ of extract. A study done by [27] found that by using different culture media, the content of flavonoid in the leaves of $M$. hirta exhibited the highest flavonoid content in the ranged from 180.79-205.42 $\mu \mathrm{g} / \mathrm{g}$ QE. However, we can deduce that from these result, the relative accumulations of both total flavonoid content are differently considered each metabolite presents in different environmental state conditions. According to [28], the variation of different flavonoid values also could be influenced by genetic variations, quantity and quality composition of the extract. Similar study by [29] showed where the values of antioxidant leaves studied were lower compared to the previous reported regards the active components of the plant vary depending on environmental, physical and chemical treatments. Last but not least, the $M$. decemfidum leaves extract showed flavonoid content in the ranged from $3.65-5.62 \mathrm{mg} /$ QE/g of extract. Research done by [28] found that the flavonoid content of $M$. decemfidum leaves extracts contain $40.67 \pm 0.036 \mathrm{mg}$ QE/g of extract in their samples which are higher than our studied samples. Moreover, interestingly in their study, they have revealed of both M. malabathricum and M. decemfidum leaves extract where they found that the M. decemfidum leaves exhibited higher flavonoid content than M. malabathricum leaves (33. $09 \pm 0.004 \mathrm{mg}$ QE/g of extract). However, in our case, we can see that the total of the flavonoid content of the three Melastoma studied samples (M. malabathricum, M. decemfidum and M. hirta) do not have a significant difference which all the values above $5.60 \mathrm{mg} / \mathrm{QE} / \mathrm{g}$ of extract. The ranking of highest total flavonoid content was in the order: $\mathrm{MD}(\mathrm{Ea})>\mathrm{CH}(\mathrm{Ea})>\mathrm{MM}(\mathrm{Ea})>\mathrm{MM}(\mathrm{Hex})>\mathrm{MD}(\mathrm{MeoH})>\mathrm{MM}(\mathrm{MeoH})>\mathrm{MD}(\mathrm{Hex})>\mathrm{CH}(\mathrm{Hex})>\mathrm{CH}(\mathrm{MeOH})$. From these results, the highest flavonoid content of each Melastoma plant can be supported through the present of the excellent bioactive compounds show this plant. Literature has been reported that, the isolation and identification of phytochemical constituents from this plant yielded quercetin, quercitrin, kaempferol-3-O-(2",6"'di-O-p-trans-coumaroyl) glucoside which responsible for the flavonoid activity [30].

Meanwhile, anthocyanins in plant, especially leave also the main source of antioxidants activity. There are numbers of the research reported such as anthocyanins profile in defatted Dabai [13], red cabbage [31], flowering tea [32], blackcurrant [33] and others. In this study, the monomeric total anthocyanins content of the three different Melastoma species (M. malabathricum, M. decemfidum and M. hirta) were determined by maintaining the $\mathrm{pH}$ in acidic medium in order to prevent oxidation. In our study, the anthocyanins content of M. malabathricum leaves extract were recorded to have in the ranged of $1.05-3.24 \mathrm{mg} / \mathrm{g}$. Meanwhile, M. hirta and M. decemfidum leaves extract exhibited in the ranged of $0.37-2.02 \mathrm{mg} / \mathrm{g}$ and $0.40-1.74 \mathrm{mg} / \mathrm{g}$ respectively. As we can see, the composition of anthocyanins content in all studied samples vary among plant species as different cultivars within species and tissues within a plant having different anthocyanin content [34]. It can be concluded that, the highest amount of anthocyanins content in all studied samples may be ascribed to their high antioxidant activities. From observations, the ranking from the highest anthocyanin content for three different Melastoma species as follows; MM (Ea) $>\mathrm{CH}$ $(\mathrm{MeOH})>\mathrm{MD}(\mathrm{MeOH})>\mathrm{MM}(\mathrm{MeOH})>\mathrm{CH}(\mathrm{Ea})>\mathrm{MM}(\mathrm{Hex})>\mathrm{MD}(\mathrm{Ea})>\mathrm{MD}(\mathrm{Hex})>\mathrm{CH}(\mathrm{Hex})$. To date, to the best of our knowledge no detailed studies have been published in the literature about the total anthocyanins content especially in the leaves of Melastomataceae family species. Moreover, in our study, both antioxidant activity of total flavonoid and anthocyanins content are influenced by the effects of solvent extractions. As you can see in Figure 1, the highest antioxidant activity of both total flavonoid and anthocyanins content recorded from M. malabathricum leaves extract are from ethyl acetate extract, followed by methanol and hexane extract. Next, $M$. hirta and $M$. decemfidum leaves extract showed both flavonoid activities was highest in ethyl acetate meanwhile anthocyanins content recorded highest in methanolic extract. On the other hand, the extraction from hexane solvent from all Melastoma leaves extract was recorded to present low antioxidant activity for both total flavonoid and anthocyanin content. It is known that the active components from all plant present different concentrations which are depending on the analytical methodologies such as solvent extraction.

Table 1. TFC and TAC antioxidant activity of M. malabathricum, M. Hirata and M. decemfidum leaves extracts

Table 1. TFC and TAC antioxidant activity of M. malabathricum, M. Hira
\begin{tabular}{|l|l|l|}
\hline Sample extract & Antioxidant activity \\
\hline & $\begin{array}{l}\text { Total flavonoid } \\
\text { content (TFC) } \\
(\mathrm{mg} / \text { QE/g of } \\
\text { extract) }\end{array}$ & $\begin{array}{l}\text { Total anthocyanin } \\
\text { content (TAC) } \\
(\mathrm{mg} / \mathrm{g})\end{array}$ \\
\hline MM-Hex & 5.03 & 1.05 \\
\hline MM-Ea & 5.65 & 3.24 \\
\hline MM-MeoH & 4.17 & 1.59 \\
\hline MH-Hex & 3.28 & 0.37 \\
\hline MH-Ea & 5.61 & 1.29 \\
\hline MH-MeoH & 2.27 & 2.02 \\
\hline MD- Hex & 3.65 & 0.40 \\
\hline MD-Ea & 5.62 & 0.93 \\
\hline MD- MeoH & 4.67 & 1.74 \\
\hline
\end{tabular}

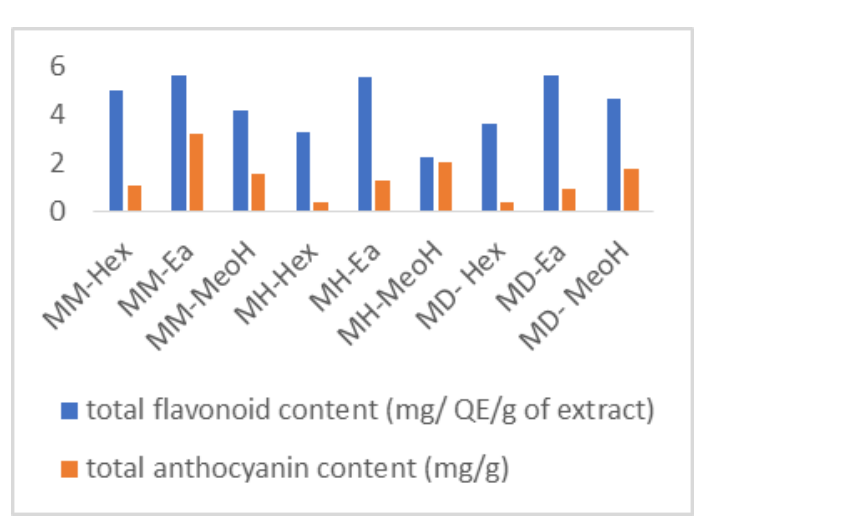

Figure 1 the antioxidant activity of three different Melastoma leaves extract

\subsection{Tyrosinase inhibition assay}

Tyrosinase is a copper-containing enzyme, which is the key enzyme of the formation of melanin. By developing tyrosinase inhibitors, especially form, plant origin can slow down the cause of hyperpigmentation, melasma, freckles and geriatric pigment spots of skin [35]. To date, the most common skin whitening and depigmentation agents available commercially are kojic acid, catechins, arbutin, hydroquinone (HQ) and azelaic acid [36]. However, some adverse effects of these compounds create major concerns among consumers due to some of these compounds are irreversible as they can cause cutaneous damage, ochronosis, etc [36]. Their numbers of study of anti-tyrosinase in the plant such as tyrosinase activity in fresh and processed leaves of cashew and betel [37], bintangur leaves [38] and 
Citation: Nur Fauwizah Azahar, et al., 2019. In Vitro Whitening Properties and Antioxidative Potentials of The Extracts of Three Melastoma Leaves Species (M. malabathricum, M. hirta and M. decemfidum). Journal of Applied Sciences Research., 15(3): 6-11. DOI: 10.22587/jasr.2019.15.3.2

the leaves and fruit of murta (Ugni molinae Turcz) [39]. According to [40] in the plant, tyrosinase is localized in the chloroplasts of healthy plant tissue, whereas its substrates are contained in the vacuole. Therefore, nowadays, natural products containing melanin synthesis inhibitory activity are one of the most interest potential cosmetics applications for skin lightening in most researchers.

In this study, all nine types of extracts were assayed using in vitro mushroom tyrosinase methods. All the percentage inhibition values were given in Table 2 below. The tyrosinase inhibition of all Melastoma leaves extract can be seen in the range from (30.7\% - $70.1 \%)$. Moreover, of all the tested Melastoma extracts, the highest inhibition and activation for tyrosinase can be found in M. malabathricum in methanolic extract. Meanwhile, the lowest percentage of inhibition tyrosinase enzyme was from M. Hirta in hexane. The ranking of highest whitening effects was in the order: MM $(\mathrm{MeOH})>\mathrm{MD}(\mathrm{MeOH})>\mathrm{MM}(\mathrm{Ea})>\mathrm{MD}(\mathrm{Ea})>$ $\mathrm{MM}(\mathrm{Hex})>\mathrm{MD}(\mathrm{Hex})>\mathrm{MH}(\mathrm{Ea})>\mathrm{MH}(\mathrm{MeOH})>\mathrm{MH}(\mathrm{Hex})$. Research done by (Vardhan et al., 2014) by using citrus lemon leaves where the inhibition of tyrosinase activity in plants extracts was influenced by the extraction of organic solvents (hexane, ethyl acetate, methanol and water). They also found that the level of inhibition tyrosinase activity was higher in methanolic extract than ethyl acetate extract in Citrus limon leaves. Therefore, our study shows a positive correlation with previous references as the highest tyrosinase activity in the leaves extracts are in a methanolic state. In this study, kojic acid and ascorbic acid were used as a positive control, as it has been calculated that the tyrosinase inhibition activities in both controls exhibit $75 \%$ and $92 \%$ respectively. Similar, result from [41] where the positive control of kojic acid displayed highest tyrosinase inhibition activity than a studied sample.

The inhibition of tyrosinase ability in the Melastoma plant against melanin can be supported from the active compound that present in the leaves and also due to hydroxyl groups of the flavonoid compounds of the plant extracts that could form a hydrogen bond to active site of the enzyme thus, leading to a lower enzymatic activity [41]. Also, the steric hindrance or changing in conformation could occur due to some tyrosinase inhibitors act through hydroxyl groups that bind to the active site. To the best of our knowledge, this is the first report on the effects of whitening activity of Melastoma plant leaves. Hence, it showed that Melastoma plant leaves especially M. malabathricum in the methanolic extract have a higher capability to act as major defence mechanism against ultraviolet light of the sun.

Table 2. Anti-tyrosinase activity of M. malabathricum, M. hirta and M. decemfidum leaves extracts

\begin{tabular}{|l|l|}
\hline Sample extract & Anti-tyrosinase activity (\%) \\
\hline MM-Hex & 44.60 \\
\hline MM-Ea & 46.55 \\
\hline MM-MeoH & 70.08 \\
\hline MH-Hex & 30.68 \\
\hline MH-Ea & 40.75 \\
\hline MH-MeoH & 33.61 \\
\hline MD- Hex & 42.73 \\
\hline MD-Ea & 45.75 \\
\hline MD- MeoH & 54.83 \\
\hline
\end{tabular}

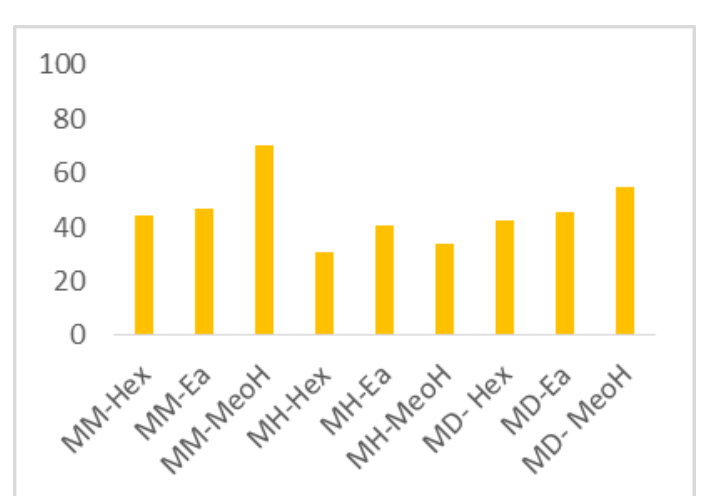

Figure 2 Anti-tyrosinase activity of three different Melastoma leaves extract

\subsection{The relationship between antioxidant and tyrosinase inhibition}

In this present works, the differences between all Melastoma leaves species (M. malabathricum, M.hirta and M.decemfidum) samples were statistically significant as showed in Table 3. From the observations, positive correlations were exhibited in between two antioxidant activity TFC and TAC in value $\left(\mathrm{r}^{2}=\right.$ 0.225). Meanwhile, it also can be seen that the antioxidant activity of TFC and TAC of all Melastoma leaves extract was positively correlated with anti-tyrosinase such as TFC $\left(r^{2}=0.326\right)$ and TAC $\left(r^{2}=0.255\right)$. The highest correlation has been found between TFC, and anti-tyrosinase activity methods is 0.326 . Therefore, it shows that the highest antioxidant activity in Melastoma plant exhibited highest level inhibition of tyrosinase activity. Moreover, it also can deduce that flavonoid and anthocyanin compounds of Melastoma plants (M. malabathhricum, M. hirta and M. decemfidum) leave extract proved to be effective inhibitors of tyrosinase activity.

Table 3. The correlations between the results of TFC, TAC and Anti-tyrosinase activity

\begin{tabular}{|l|l|l|l|}
\hline Correlation & TFC & TAC & $\begin{array}{l}\text { Anti- } \\
\text { tyrosinase } \\
\text { activity }\end{array}$ \\
\hline TFC & 1.000 & & \\
\hline TAC & $0.225^{* *}$ & 1.000 & \\
\hline Anti-tyrosinase & $0.326^{* *}$ & $0.255^{* *}$ & 1.000 \\
\hline
\end{tabular}

** Significant at $\mathrm{p}<0.05$

\section{CONCLUSION}

From this study, the total flavonoid and anthocyanin content of all three Melastoma leaves extract (M. malabathricum, M. hirta and M. decemfidum) were successfully studied. Based on the results, the amounts of flavonoid and anthocyanin content were influenced by the type of extraction solvent used where mostly ethyl acetate and methanol exhibited the highest amount of TFC and TAC. Meanwhile, tyrosinase inhibition of all studied samples showed good tyrosinase activity where M. malabathricum in the methanolic extract was recorded to be the highest to inhibit in vitro mushroom tyrosinase activity. A positive correlation $(\mathrm{P}<0.05)$ 
Citation: Nur Fauwizah Azahar, et al., 2019. In Vitro Whitening Properties and Antioxidative Potentials of The Extracts of Three Melastoma Leaves Species (M. malabathricum, M. hirta and M. decemfidum). Journal of Applied Sciences Research., 15(3): 6-11. DOI: 10.22587/jasr.2019.15.3.2

has been shown in between antioxidant activity of TFC, TAC and tyrosinase activity. Hence, antioxidants activity of all three Melastoma leaves extracts incorporated with a good inhibition of tyrosinase activity could be clear potentials for fulfilling the needs for alternatives remedy used in cosmeceuticals and medicinal applications.

The authors declare that they have no competing of interest.

\section{CONFLICT OF INTEREST}

ACKNOWLEDGEMENT

The authors gratefully acknowledge the financial support from FRGS grant and Graduate Research Fellowship (GRF) under UPM for the scholarship.

\section{REFERENCES}

[1] Narayanaswamy, N., Duraisamy, A., \& Balakrishnan, K. P. (2011). Screening of some medicinal plants for their antityrosinase and antioxidant activities, $3(2), 1107-1112$.

[2] Chiari, M. E., Joray, M. B., Ruiz, G., Palacios, S. M., \& Carpinella, M. C. (2010). Tyrosinase inhibitory activity of native plants from central Argentina : Isolation of an active principle from Lithrea molleoides. Food Chemistry, 120(1), 10-14. https://doi.org/10.1016/j.foodchem.2009.09.061

[3] Abd Rahim, A., Jamaludin, M., \& Alias, Z. (2014). Antidiabetic activity of aqueous extract of leptospermum flavescens in alloxan induced diabetic rats. Sains Malaysiana, 43(9), 1295-1304.

[4] Azahar, N. F., Abd Gani, S. S., \& Mohd Mokhtar, N. F. (2017). Optimization of phenolics and flavonoids extraction conditions of Curcuma Zedoaria leaves using response surface methodology. Chemistry Central Journal, 11(96), 1-10. https://doi.org/10.1186/s13065-017-0324-y

[5] Bisht Satpal Singh, Priya, K. . R., Rojita, M., Amrita, P., \& Praveen, B. . (2012). Antimicrobial properties of few plants used in traditional system of medicine. International Journal of Research in Ayurveda \& Pharmacy, 3(4), 563-564.

[6] Lakshmi, S., Padmaja, G., \& Remani, P. (2011). Antitumour effects of isocurcumenol isolated from curcuma zedoaria rhizomes on human and murine cancer cells, 2011. https://doi.org/10.1155/2011/253962

[7] Chang, C., Chang, W., Hsu, J., Shih, Y., \& Chou, S. (2013). Chemical composition and tyrosinase inhibitory activity of Cinnamomum cassia essential oil, 28.

[8] Haron, N. W., Anuar, N., \& Veeramohan, R. (2015). The taxonomic significance of leaf micromorphology in the genus Melastoma L. (Melastomataceae). Sains Malaysiana, 44(5), 643-650.

[9] Alnajar, Z. A. A., Abdulla, M. A., Ali, H. M., Alshawsh, M. A., \& Hadi, A. H. A. (2012). Acute toxicity evaluation, antibacterial, antioxidant and immunomodulatory effects of melastoma malabathricum. Molecules, 17, 3547-3559. https://doi.org/10.3390/molecules 17033547

[10] Danladi, S., Wan-Azemin, A., Sani, Y. N., Mohd, K. S., Us, M. R., Mansor, S. M., \& Dharmaraj, S. (2015). Phytochemical screening, total phenolic and total flavonoid content, and antioxidant activity of different parts of Melastoma malabathricum. Jurnal Teknologi, 77(2), 63-68.

[11] Basu, S., Pal, B., \& Mandal, N. C. (2016). Antimicrobial and antioxidant activities of two endophytic fungi isolated from melastoma malabathricum 1 . leaves. International Journal of Current Pharmaceutical Research, 8(3), 3-7.

[12] Zakaria, Z. A., Rofiee, M. S., Mohamed, A. M., Teh, L. K., \& Salleh, M. Z. (2011). In vitro antiproliferative and antioxidant activities and total phenolic contents of the extracts of melastoma malabathricum leaves. Journal of Acupuncture and Meridian Studies, 4(4), $248-256$. https://doi.org/10.1016/j.jams.2011.09.016

[13] Khoo, H. ., Azlan, A., Ismail, A., \& Abas, F. (2013). Response surface methodology optimization for extraction of phenolics and antioxidant capacity in defatted dabai parts. Sains Malaysiana, 42(7), 949-954.

[14] Stankovic, M. S. (2011). Total phenolic content, flavonoid concentration and antioxidant activity of Marrubium peregrinum L . extracts. Kragujevac J. Sci, $33,63-72$.

[15] Citation Missing

[16] Sadeghi, Z., Valizadeh, J., Shermeh, O. A., \& Akaberi, M. (2015). Antioxidant activity and total phenolic content of Boerhavia elegans ( choisy ) grown in Baluchestan, Iran. Avicenna Journal of Phytomedicine, 5(1), 1-9.

[17] Mierziak, J., Kostyn, K., \& Kulma, A. (2014). Flavonoids as important molecules of plant interactions with the environment. Molecules, 19, 16240-16265. https://doi.org/10.3390/molecules191016240

[18] Panche, A. ., Diwan, A. ., \& Chandra, S. . (2016). Flavonoids: an overview. Journal of Nutritional Science, 5(47), 1-15. https://doi.org/10.1017/jns.2016.41

[19] Alam, M. A., Syazwanie, N. F., Mahmod, N. H., Badaluddin, N. A., Ain Mustafa, K., Alias, N., ... Prodhan, M. A. (2018). Evaluation of antioxidant compounds , antioxidant activities and capsaicinoid compounds of Chili ( Capsicum sp .) germplasms available in Malaysia. Journal of Applied Research on Medicinal and Aromatic Plants, In press. https://doi.org/10.1016/j.jarmap.2018.02.001

[20] Hayat, M., Abbas, M., Munir, F., Hayat, M. Q., Keyani, R., \& Amir, R. (2017). Potential of plant flavonoids in pharmaceutics and nutraceutics. J Biomol Biochem, 1(1), 12-17.

[21] Ghasemzadeh, A., Jaafar, H. Z. E., \& Rahmat, A. (2010). Antioxidant activities, total phenolics and flavonoids content in two varieties of Malaysia young ginger (Zingiber officinale Roscoe). Molecules, 15, 4324-4333. https://doi.org/10.3390/molecules 15064324

[22] Ming, Z. Z., Wei, W., Jiao, L.-L., Ping, F. Y., \& Ming, Q. G. (2015). Analysis of flavonoids in lotus ( Nelumbo nucifera ) leaves and their antioxidant activity using macroporous resin chromatography coupled with LC-MS/MS and Antioxidant Biochemical Assays. Molecules, 20, $10553-10565$. https://doi.org/10.3390/molecules200610553

[23] Moustafa, A. E. A., El-azeem, H. A., Omran, M. A., Nasr, S. A. M., Nabi, I. M. A., \& Teleb, Z. A. (2015). Two flavonoid compounds isolated from Nepeta septemcrenata growing in South Sinai ,Egypt. American Journal of Ethnomedicine, 2(3), 143-156.

[24] Arnnok, P., Ruangviriyachai, C., Mahachai, R., Techawongstien, S., \& Chanthai, S. (2012). Determination of total phenolics and anthocyanin contents in the pericarp of hot chilli pepper ( Capsicum annuum L .). International Food Research Journal, 19(1), 235-243.

[25] Horbowicz, M., Kosson, R., Grzesiuk, A., \& Debski, H. (2008). Anthocyanins of fruits and vegetables - their occurrence , analysis and role in human nutrition. Vegetable Crops Research Bulletin, 68, 5-22. https://doi.org/10.2478/v10032-008-0001-8

[26] Chanda, S. V, \& Nagani, K. V. (2010). Antioxidant capacity of Manilkara Zapota L . leaves extracts evaluated by four in vitro methods. Nature and Science, $8(10), 260-266$.

[27] Lopez, T., Corbin, C., Falguieres, A., Doussot, J., Hano, C., Montguillon, J., ... Laine, E. (2016). Secondary metabolite accumulation , antibacterial and antioxidant properties of in vitro propagated Clidemia hirta L . extracts are in fl uenced by the basal culture medium In fl uence de la composition du milieu de culture sur la pr. Comptes Rendus Chimie, 19, 1071-1076. https://doi.org/10.1016/j.crci.2016.03.012

[28] Hamid Abd, H., Ramli, A. N. M., Zamri, N., \& Yusoff M, M. (2018). UPLC-QTOF / MS-based phenolic profiling of Melastomaceae , their antioxidant activity and cytotoxic e ff ects against human breast cancer cell. Food Chemistry, 265(May), 
[29] Ifesan, B. O. T., Fashakin, J. F., Ebosele, F., \& Oyerinde, A. . (2013). Antioxidant and Antimicrobial properties of selected plant leaves. European Journal of Medicinal Plants, 3(3), 465-473.

[30] Susanti, D., Sirat, H. M., Ahmad, F., \& Ali, R. M. (2008). Bioactive constituents from the leaves of Melastoma Malabathricum L. Jurnal Ilmiah Farmasi, $5(1), 1-8$.

[31] Wiczkowski, W., Szawara-nowak, D., \& Topolska, J. (2015). Changes in the content and composition of anthocyanins in red cabbage and its antioxidant capacity during fermentation, storage and stewing. Food Chemistry, 167, 115-123. https://doi.org/10.1016/j.foodchem.2014.06.087

[32] Xiaowei, H., Xiaobo, Z., Jiewen, Z., Jiyong, S., Xiaolei, Z., \& Holmes, M. (2014). Measurement of total anthocyanins content in flowering tea using near infrared spectroscopy combined with ant colony optimization models. Food Chemistry, 164, 536-543. https://doi.org/10.1016/j.foodchem.2014.05.072

[33] Nour, V., Stampar, F., Veberic, R., \& Jakopic, J. (2013). Anthocyanins profile, total phenolics and antioxidant activity of black currant ethanolic extracts as influenced by genotype and ethanol concentration. Food Chemistry, 141(2), 961-966. https://doi.org/10.1016/j.foodchem.2013.03.105

[34] Wang, Y., Zhu, J., Meng, X., Liu, S., Mu, J., \& Ning, C. (2016). Comparison of polyphenol , anthocyanin and antioxidant capacity in four varieties of Lonicera caerulea berry extracts. Food Chemistry, 197, 522-529. https://doi.org/10.1016/j.foodchem.2015.11.006

[35] Ya, W., Chun-meng, Z., Tao, G., Yi-lin, Z., \& Ping, Z. (2015). Preliminary screening of 44 plant extracts for anti-tyrosinase and antioxidant activities. Pak. J. Pharm. Sci., 28(5), 1737-1744.

[36] Jennifer, C., Stephie, C. ., Abhishri, S. ., \& Shalini, B. . (2012). A Review on skin whitening property of plant extracts. International Journal of Pharma and Bio Sciences, 3(4), 332-347.

[37] Tan, Y. P., \& Chan, E. W. C. (2014). Antioxidant, antityrosinase and antibacterial properties of fresh and processed leaves of Anacardium occidentale and Piper betle. Food Bioscience, 6, 17-23.

[38] Govindappa, M., Hemashekhar, B., Arthikala, M., Rai, V. R., \& Ramachandra, Y. L. (2018). Characterization, antibacterial, antioxidant, antidiabetic, antiinflammatory and antityrosinase activity of green synthesized silver nanoparticles using Calophyllum tomentosum leaves extract. Results in Physics, 9, 400408. https://doi.org/10.1016/j.rinp.2018.02.049

[39] De Dicastillo, C. L., Bustos, F., Valenzuela, X., López-carballo, G., Vilariño, J. M., \& Galotto, M. J. (2017). Chilean berry Ugni molinae Turcz . fruit and leaves extracts with interesting antioxidant, antimicrobial and tyrosinase inhibitory properties. Food Research International, 102, 119-128. https://doi.org/10.1016/j.foodres.2017.09.073

[40] Vardhan, A., Khan, S., \& Pandey, B. (2014). Screening of plant parts for anti-tyrosinase activity by tyrosinase assay using mushroom tyrosinase. Indian J. Sci. Res, 4(1), 134-139.

[41] Thach, B. D., Dao, V. Q., Giang, T. T. L., Cang, D. T., Linh, L. N. T., Ben, T. T., ... Suong, N. K. (2017). Antioxidant and antityrosinase activities of flavonoid from Blumea Balsamifera ( L .) DC . Leaves. European Journal of Research in Medical Sciences, 5(1), 1-6. 